NASA TECHNICAL NOTE

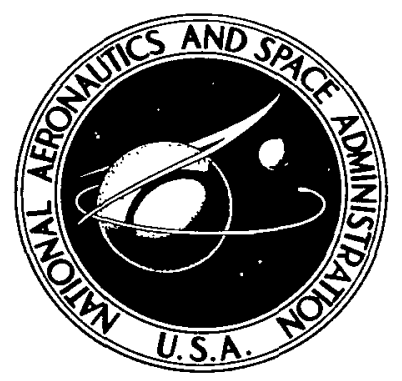

NASA IN D-8460 R.1

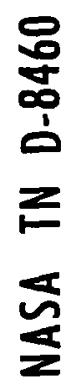

LOA. $1:$ SETL E AFWL TECHMICAL L KIRTLAND AFB, I

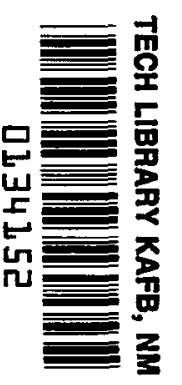

X-RAY PHOTOELECTRON SPECTROSCOPIC STUDY OF SURFACE CHEMISTRY OF DIBENZYL-DISULFIDE ON STEEL UNDER MILD AND SEVERE WEAR CONDITIONS

Donald R. Wheeler

Lewis Research Center

Cleveland, Obio 44135

NATIONAL aERONAUTICS AND SPACE ADMINISTRATION - WASHINGTON, D. C. - MAY 1977 


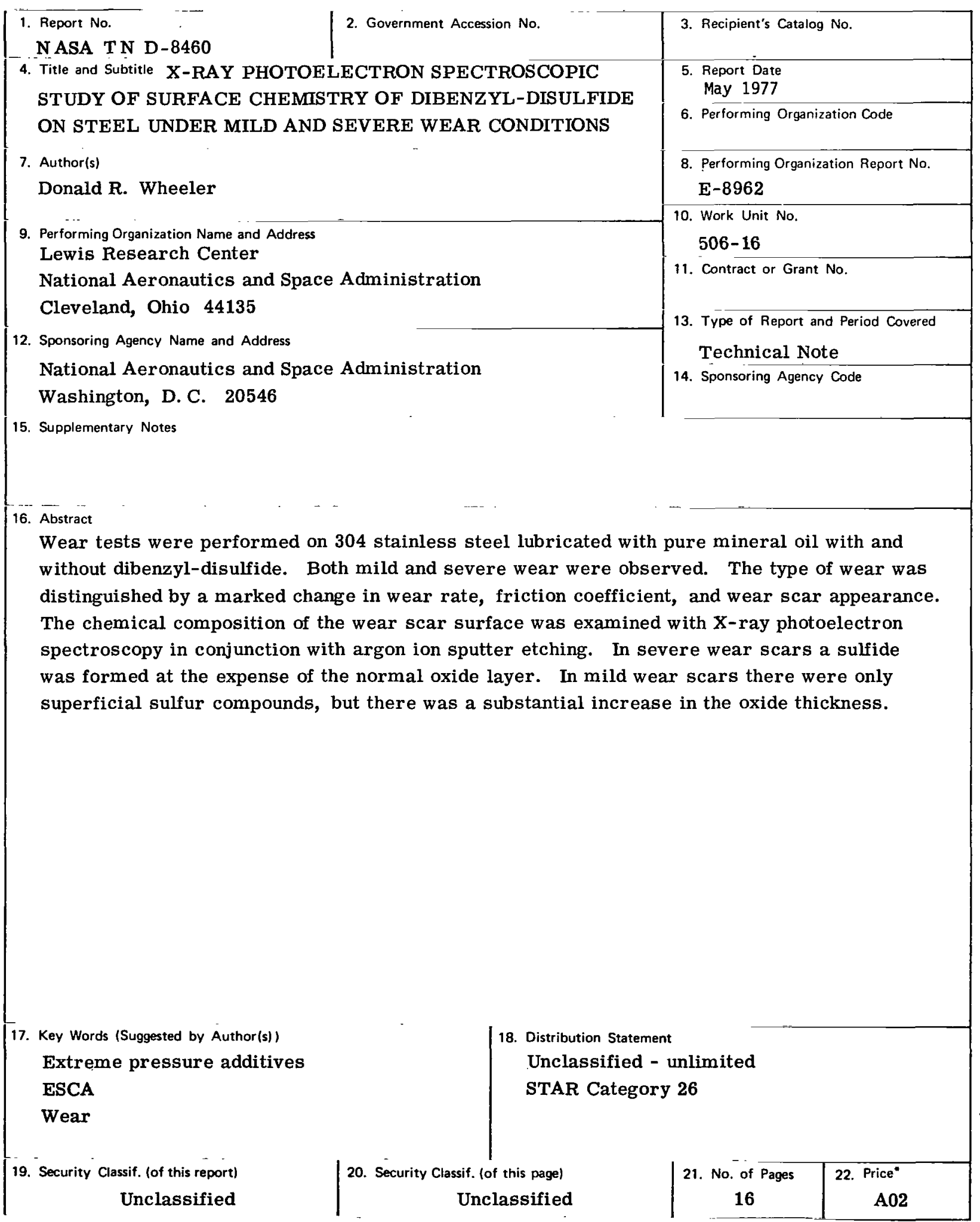

* For sale by the National Technical Information Service, Springfield, Virginia 22161 


\title{
X-RAY PHOTOELECTRON SPECTROSCOPIC STUDY OF SURFACE CHEMISTRY OF DIBENZYL-DISULFIDE ON STEEL UNDER MILD AND SEVERE WEAR CONDITIONS
}

\author{
by Donald R. Wheeler
}

Lewis Research Center

\begin{abstract}
SUMMARY
$\mathrm{X}$-ray photoelectron spectroscopy was used to characterize the chemical composition of 304 stainless steel surfaces run in oil containing dibenzyl-disulfide under both mild and severe wear conditions. In severe wear a sulfide was formed at the expense of the normal oxide. This was due to either chemical attack on the oxide or reaction with clean metal exposed by the wear process. In the mild wear scars there was no evidence of either sulfide or mercaptide. The oxide, however, was approximately twice as thick as the normal oxide on an unworn surface. The change in surface chemistry was primarily a function of wear rate rather than load.
\end{abstract}

\section{INTRODUCTION}

In lubrication of contacts under high load at low velocity there is a high probability of oil film breakdown. It is common practice to include extreme pressure (ep) additives in oil intended for this kind of application. Sulfur, in a wide variety of organic molecules, is a widely used ep additive; however, the surface chemistry of sulfur additives on steel during rubbing is at best poorly understood.

The thorough study of the load carrying ability of simple organic sulfur additives by Allum and Ford (ref. 1) and Allum and Forbes (ref. 2) indicates that sulfur additives are effective in two distinct wear regimes. They may function as ep additives to prevent the onset of severe wear at high loads, and they may act as antiwear additives in the mild wear regime at lighter loads. Organic disulfides are effective in both regimes, with effectiveness in preventing severe wear being correlated with the ease of carbon-sulfur bond scission. Dibenzyl-disulfide (DBDS) is one of the most effective ep additives. It is, on the other hand, a rather poor antiwear additive. Effectiveness in 
preventing mild wear correlates with ease of sulfur-sulfur bond breakage.

Allum and Forbes (ref. 3) used electron probe microanalysis (EPMA) to measure elemental concentrations in wear scars. In the ep region the amount of sulfur generally increased with load, and the better ep additives gave proportionately more sulfur. In the antiwear regime much less sulfur was present.

As a result of the work in references 1 to 3 and many static immersion tests (e.g., ref. 4), a general theory of disulfide additive chemistry has been proposed: under mild wear conditions sulfur-sulfur bond breakage at the metal surface results in iron mercaptide, which is the effective antiwear layer; with increasing load, more severe wear, and presumably higher contact temperatures, carbon-sulfur bond breakage in the mercaptide results in a layer containing sulfur (perhaps iron sulfide), which is the effective ep layer.

With the availability of X-ray photoelectron spectroscopy (XPS), it has become possible to obtain more complete chemical information about surface layers than just the elemental concentrations provided by EPMA. Two recent studies have applied XPS to the surfaces of metals run under ep conditions in oils containing sulfur additives. Baldwin (refs. 5 and 6) tested a wide range of commercial additives in the Falex tester. He found no consistent pattern of surface chemical changes except in the sulfur content. In the case of sulfur he found that all additives produced what is probably iron sulfide in concentrations inversely proportional to the amount of wear they produced.

Bird and Galvin (ref. 7) used XPS to analyze the surface of both rubbing and immersion test specimens. They used sulfur, DBDS, and zinc dialkyl dithiophosphate as additives. Immersion in DBDS at $145^{\circ} \mathrm{C}$ resulted in a sulfate layer on the surface but no sulfide. Rubbing tests produced both sulfate and sulfide, the sulfide being the predominant species. One specimen that had been immersed in zinc dialkyl dithiophosphate solution was ion etched to determine its composition as a function of depth. The sulfate decreased very rapidly compared with the other film constituents.

Because of the limited applicability of immersion tests, the difficulty of surface chemical analysis, even when XPS is employed, and the frequent lack of specification of the wear regime involved in testing, there is still considerable disagreement as to the chemistry of organic disulfides in rubbing contacts. The roles of the oxide layer and oxygen are particularly unclear (e.g., ref. 8 and discussions in refs. 1 and 9).

The objective of the experiment described in this report was to use XPS to study the surface chemistry of 304 stainless steel rubbed in a solution of DBDS in USP mineral oil. The load was varied from 0.5 to 25 kilograms and produced both mild and severe wear. Tests were performed at room temperature in laboratory air. Ion sputter etching was used extensively for surface cleaning and to determine composition as a function of depth. 


\section{MATERIALS}

Wear tests were performed on a pair of austenitic 304 stainless steel specimens consisting of a hemispherical rider with a radius of 0.5 centimeter and a flat 6-centimeter-diameter disk. The steel contained 18 to 20 percent chromium, 8 to 12 percent nickel, and less than 0.08 percent carbon. Its hardness was Rockwell A-49. The specimens were ground on emery paper to 600 grit and then polished with 3-micrometer diamond polish. They were ultrasonically cleaned in trichlorotrifluoroethylene just before the wear tests.

The base oil used in the tests was a commercial USP mineral oil with the properties listed in table I. The DBDS was specified to have a melting point of $70^{\circ}$ to $72^{\circ} \mathrm{C}$ and was used as received. The concentration for all tests was 0.25 percent sulfur by weight prepared by dissolving 0.96 gram of DBDS in 99 grams of oil. The oil was heated to $60^{\circ} \mathrm{C}$ to speed the solution of the additive, but ras cooled over night before use.

\section{APPARATUS}

The apparatus used was a modified shaper machine shown in figure 1. The disk was immersed in the oil solution, while the rider was rubbed back and forth on the disk by the shaper ram. Its maximum velocity was 0.15 centimeter per second, and its travel was about 0.5 centimeter. At each oscillation the flat was moved 0.127 millimeter ( 0.005 in. ) transverse to the rider motion. When the flat had moved 0.5 centimeter, its motion was reversed. Each test consisted of 20 such transverse passes of the disk under the moving rider. The result was a wear scar 0.5 by 0.5 centimeter on the disk. After each test the disk and rider could be turned so that fresh areas were in contact for the next test.

The torque on the disk (which was proportional to the friction force) was measured by a quartz crystal load cell and displayed on a chart recorder. The load on the contact was provided by weights on the rider support arm. It ranged from 5 to $250 \mathrm{~N}$. The diameter of the wear scar on the rider was measured after each test to assess wear.

The wear scars on the disks were analyzed chemically by XPS. The principles of XPS are discussed in references 10 and 11. Briefly, they are as follows: X-ray photons striking an atom cause it to emit an electron. The electron leaves the atom with a kinetic energy $\mathrm{K}$, which is the difference between the incident photon energy $\mathrm{h} \nu$ and the binding energy $E_{\mathbf{B}}$ of the electron in the atom: $\mathbf{K}=\mathrm{h} \nu-\mathrm{E}_{\mathbf{B}}$. The binding energy is characteristic of the atom excited and in addition depends slightly on the oxidation state of the atom. Thus, if the electron energies $\mathrm{K}$ emitted from a sample are measured and $\mathrm{h} \nu$ is known, the atoms in the sample may be identified and some chemical information extracted by comparing the measured binding energies with binding energies mea- 
sured previously on standard samples. Because of the low kinetic energies (less than $2 \mathrm{keV}$ ) of the electrons, the atoms more than 2 nanometers (20 ̊) below the surface of a solid cannot escape to contribute to the spectrum.

The particular apparatus used in this study consisted of a commercial electron energy analyzer and X-ray source in a vacuum system designed to accommodate a variety of samples. An ion gun was incorporated in the system so that the sample surface could be gradually sputtered away and the composition determined as a function of depth. The pressure in the vacuum system was below $1.33 \times 10^{-6}$ pascal except during sputtering, when it was $5.3 \times 10^{-3}$ pascal of argon.

The $\mathrm{X}$-ray source had a magnesium target with a characteristic $\mathrm{MgK}_{\alpha}$ energy $\mathrm{h} \nu$ of 1253. 6 electron volts. It was operated at 10 kilovolts and 40 milliamperes and was regulated in such a way that the $\mathrm{X}$-ray flux was held constant despite voltage fluctuations. The electron energy analyzer consisted of a retarding grid and a double-pass cylindrical mirror analyzer (CMA). The energy of electrons passed by the CMA was fixed at 25 electron volts for these experiments, and the retarding grid voltage was increased linearly with time. This voltage drove the $\mathrm{x}$-axis of an $\mathrm{x}, \mathrm{y}$-recorder. Electrons passing through the CMA caused pulses in an electron multiplier. These pulses were fed to a ratemeter which drove the $y$-axis of the $\mathrm{x}, \mathrm{y}$-recorder. The recorder thus plotted a spectrum of electrons per second against energy. All the analyzed electrons came from a spot 2 millimeters in diameter on the sample.

Figure 2 shows a typical oxygen (1s) peak in the spectrum. The spectrum is from a wear test specimen. The binding energies assigned to chemical compounds are taken from the literature and are identified in table II. These binding energies are accurate to about \pm 0.3 electron volt, the error being in the relative calibration of the different electron energy analyzers used.

Overlapped peaks such as those of oxygen in figure 2 were resolved with an analog curve resolver. It was possible to resolve three distinct peaks for iron oxides $\left(\mathrm{Fe}_{2} \mathrm{O}_{3} / \mathrm{FeO}\right)$, chromic oxides $\left(\mathrm{Cr}_{2} \mathrm{O}_{3}\right)$, and adsorbed oxygen $\left(\mathrm{O}_{2}\right)$ in figure 2 . In the same way, the metallic iron peak was extracted from the several lower energy iron peaks that develop in iron oxide.

\section{PROCEDURE}

The wear tests were performed immediately after the specimen was cleaned. In all tests the ambient atmosphere was the laboratory air. After each test the rider was rinsed in trichlorotrifluoroethylene, and a photomicrograph of the wear scar was obtained. It and the disk were then turned so that two unworn spots were in contact, and a new test was run. After completion of a series of tests the rider and disk were rinsed thoroughly in trichlorotrifluoroethylene and immediately placed in the spectrometer 
vacuum chamber for analysis.

Argon ion sputtering of the sample was accomplished by backfilling the vacuum chamber to $5.3 \times 10^{-3}$ pascal with argon. The ion gun was operated at 2 kilovolts. The sputtering rate was several nanometers per minute, but was not known accurately.

\section{RESULTS}

When the riders were examined microscopically after a wear test, two distinctly different types of wear scars were seen. Examples are shown in figure 3. The mild wear scar was smooth and featureless, was always less than 0.4 millimeter in diameter, and occurred in tests where the friction coefficient was approximately 0.1 . The severe wear scar showed evidence of adhesive wear and plowing, was always greater than 0.4 millimeter in diameter, and resulted from tests where the friction coefficient was about 0.3 .

The load above which severe wear occurred was in the range 2 to 6 kilograms. The surface finish and crystallography of the particular contact region and the random presence of abrasive particles probably were important factors in determining the wear regime. As shown later in this section, the wear rate rather than the load was the variable determining surface chemistry.

The wear scars on the disk were analyzed by XPS, as described in the section APPARATUS. Figure 4 shows typical sulfur (2p) and oxygen (1s) spectra. The sulfur peaks can be identified by reference to table $\Pi$ as iron sulfide, probably $\mathrm{FeS}$ or $\mathrm{FeS}_{2}$, at 161.0 electron volts and as iron sulfate $\left(\mathrm{FeSO}_{4}\right)$ at 167.8 electron volts. With no sputter etching both peaks occurred, but 30 seconds of etching virtually eliminated the sulfate peak and left an appreciable amount of sulfide only on the severe wear scar.

The oxygen (ls) spectrum was resolved into three peaks with the curve resolver. Two at 529. 0 and 530.6 electron volts are identified as iron and chromium oxides, probably $\mathrm{FeO}$ or $\mathrm{Fe}_{2} \mathrm{O}_{3}$ and $\mathrm{Cr}_{2} \mathrm{O}_{3}$, respectively. The remaining peak at 531.1 electron volts was apparently a surface contaminant, since it was almost entirely removed by 30 seconds of sputter etching. It was attributed to adsorbed oxygen.

A general result of 30 seconds of sputtering was a large decrease in the carbon adsorbed oxygen and sulfate peaks and an associated dramatic increase in the sulfide and oxide peaks. We therefore attributed the former to surface contaminants which dominated in the first few atomic layers and prevented the escape of electrons from the underlying film of oxide and sulfide. Accordingly we considered 30 seconds of ion etching to be the final cleaning process and were concerned primarily with the underlying films.

In table III the heights of the two oxide peaks after several sputtering times are shown as percentages of the total oxide peak height. The 530.6-electron-volt peak $\left(\mathrm{Cr}_{2} \mathrm{O}_{3}\right)$ is 23 to 25 percent of the total oxide. This percentage is probably not signifi- 
cantly more than the 18 to 20 percent chromium in 304 stainless steel, and it does not change with sputtering time.

The heights of the 161-electron-volt (sulfide) peak and the 529-electron-volt (oxide) peaks after 30 seconds of sputtering are plotted as a function of wear scar diameter in figure 5. There is a distinct difference between the mild and severe wear regions in both the oxide and sulfide concentrations. Severe wear situations result in a decrease in oxide peak height and an increase in the sulfide peak.

Depth profiles of the oxide, sulfide, and iron were produced by plotting the peak heights for the 529-, 161-, and 706-electron-volt peaks as a function of sputtering time. This was done for a severe wear scar, a mild wear scar, and an unworn surface. The results are shown in figures 6 to 8 .

Figure 6 indicates a surface layer of sulfide only in severe wear. The mild wear profile does not differ significantly from that for the unworn surface. The severe wear sulfide layer falls to one-half of its maximum value in about 1.5 minutes of sputtering. This half-maximum-thickness sputtering time serves as a rough indicator of film thickness.

Figure 7 shows significant differences among the oxygen profiles. When compared with the unworn surface oxide the severe wear oxide layer is substantially reduced in thickness. The mild wear oxide, on the other hand, is enhanced.

Finally, figure 8 shows metallic iron (as opposed to iron as an oxide or sulfide) beginning to appear most rapidly in the severe wear scar and least rapidly in the mild wear scar. Since the metallic iron peak is reduced by the presence of oxide or sulfide layers, which absorb electrons from the underlying metal, the metallic iron peak height is inversely related to the thickness of this covering layer.

\section{DISCUSSION}

\section{Severe Wear}

The wear test results all indicate the existence of two quite distinct wear regimes in these experiments. When our results are compared with those of others, it is important to know which regime is the comparable one. Some of the EPMA results of Allum and Forbes (ref. 3) and the XPS analyses of Baldwin (refs. 5 and 6) clearly apply to severe wear specimens. Bird and Galvin are not explicit on this point. Their test specimens were much harder than those used in this study, their wear test geometry differed, and the loads used were higher (up to four times) than the largest used in this study. From the high loads and the presence of sulfide in their wear scars we conclude that their test is best compared with our severe wear results.

Our severe wear results agree with these previous studies in finding sulfide in the 
wear scar. In addition, we find an accompanying decrease in the amount of oxide compared with that in the unworn specimen. This result was inferred by Allum and Forbes (ref. 3) but not directly measured. The sulfide and oxide depth profiles of figures 6 and 7 show that this oxide deficiency is not due to sulfide formed over the original oxide, but that the sulfide and oxide exist together in a layer thinner than the unworn oxide layer.

Since in Bird and Galvin's work (ref. 7) immersion of specimens in DBDS solution produced no sulfide on the specimen surface, one is led to think that the sulfide formed on clean metal in place of the oxide that had been removed by the wear process. However, their immersion tests were done at $145^{\circ} \mathrm{C}$. In an auxiliary experiment conducted at Lewis we found sulfide was the predominant surface species on iron specimens immersed for 1 minute in DBDS oil at temperatures above $200^{\circ} \mathrm{C}$. Thus, sulfide could form by corrosive attack at the oxide surface, provided that flash temperatures at the contact were high enough. It would not be surprising to find both replacement of worn oxide and corrosive attack occurring, depending on the contact conditions. We have no way of distinguishing between the two possibilities. Replacement is presumably the basis of ep additive action, while corrosion is a detrimental side effect.

\section{Mild Wear}

The antiwear properties of the additive are of major importance in the mild wear regime. While DBDS is not among the best antiwear additives, it does provide some improvement over straight oil (ref. 2). It is interesting, therefore, that the only significant change that occurs in the mild wear scars is the increase in the thickness of the oxide layer which is evident from figures 7 and 8 . In figure 7, the oxide half-maximumthickness sputtering time is 1.5 minutes for the unworn oxide and 2.2 minutes for the mild wear scar. Figure 8 can be used the same way by comparing the sputtering times required to bring the metallic iron peaks to one-half of their ultimate values, $0.75 \mathrm{~min}$ ute for the unworn surface and 1.5 minutes for the mild wear scar. Both sets of data indicate that the oxide layer on the mild wear scar is 50 to 100 percent greater than that on the unworn surface.

EPMA results in the mild wear region (ref. 3) show 15 times less sulfur than in the severe wear region. The reduction we see is only a factor of 8 to 10, but this difference could be due to the greater surface sensitivity of XPS.

While the increase in oxide thickness is the most apparent change here and while it could account for antiwear properties, the most widely accepted theory of antiwear action supposes only an adsorbed organic or an iron mercaptide layer to be the effective boundary lubricant. No evidence of a sulfur peak with binding energy appropriate to DBDS or benzyl mercaptide was found, but a fraction of a monolayer would be most dif- 
ficult to detect in the presence of the other sulfur peaks present previous to the initial sputtering. Also, the layer might not persist during transfer from the wear test apparatus to the XPS spectrometer, or it might be volatile in the spectrometer vacuum.

\section{Other Observations}

Comparison of the relative heights of the $\mathrm{Fe}_{2} \mathrm{O}_{3} / \mathrm{FeO}$ and $\mathrm{Cr}_{2} \mathrm{O}_{3}$ peaks among the three wear situations in table III and with the composition of 304 stainless steel indicates that there is probably no noticeable change in the alloy composition at the surface as a result of wear.

Finally, it is clear that the load used in the wear test is not the factor controlling the surface chemistry except as it determines the nature of the wear. This was illustrated by an auxiliary wear experiment run with $440-\mathrm{C}$ stainless steel. Loads up to 25 kilograms produced only mild wear, and analysis revealed no sulfide in the wear scars.

\section{CONCLUSIONS}

An X-ray photoelectron spectroscopic study was conducted on the surface chemistry of dibenzyl-disulfide on steel under mild and severe wear conditions. Cleaning and depth profiling by ion sputtering were used to develop new information on the antiwear regime and the nature of the oxide layer. The following conclusions were drawn:

1. A sulfide is created in severe wear scars formed in oil containing dibenzldisulfide (DBDS). This sulfide formation occurs at the expense of the natural oxide by chemical corrosion above $200^{\circ} \mathrm{C}$ as well as by replacement of worn away oxide.

2. In mild wear very little sulfide occurs in the wear scar. There is also no evidence for a monolayer of DBDS or benzyl mercaptide. This could be due to the insensitivity of the technique, to the fact that DBDS is a poor antiwear additive, or to the fact that such layers are not generally present during mild wear. There is an oxide layer 50 to 100 percent thicker than that on the unworn surface.

3. The transition from mild to severe wear surface chemistry does not depend on load except as the load determines the type of wear.

4. No change in alloy composition such as that due to surface segregation or selective reaction with chromium or iron occurs.

National Aeronautics and Space Administration,

Lewis Research Center,

Cleveland, Ohio, January 18, 1977, 506-16. 


\section{REFERENCES}

1. Allum, K. G. ; and Ford, J. F.: The Influence of Chemical Structure on the LoadCarrying Properties of Certain Organo-Sulfur Compounds. J. Inst. Petr., vol. 51, 1965, pp. 145-161.

2. Allum, K. G. ; and Forbes, E. S.: The Load-Carrying Properties of Organic Sulfur Compounds. Part II. The Influence of Chemical Structure on the Anti-Wear Properties of Organic Disulfides. J. Inst. Petr., vol. 53, 1967, pp. 173-185.

3. Allum, K. G.; and Forbes, E. S.: The Load Carrying Mechanism of Organic Sulfur Compounds - Application of Electron Probe Microanalysis. ASLE Trans., vol. 11, no. 2, 1968, pp. 162-175.

4. Forbes, E. S. ; and Reid, A. J. D.: Liquid Phase Adsorption/Reaction Studies of Organo-Sulfur Compounds and Their Load-Carrying Mechanism. ASLE Trans., vol. 16, no. 1, 1973, pp. 50-57.

5. Baldwin, Bernard A. : Chemical Characterization of Wear Surfaces Using X-Ray Photoelectron Spectroscopy. Lubr. Eng., vol. 32, no. 3, Mar. 1976, pp. 125130.

6. Baldwin, Bernard A.: Relationship Between Surface Composition and Wear: An X-Ray Photoelectron Spectroscopic Study of Surfaces Treated With Organosulfur Compounds. ASLE Preprint 75-LC-2D-4, Oct. 1975.

7. Bird, R. J.; and Galvin, G. D.: The Application of Photoelectron Spectroscopy to the Study of e.p. Films on Lubricated Surfaces. Wear, vol. 37, 1976, pp. 143167.

8. Buckley, Donald H.: Oxygen and Sulfur Interactions With a Clean Iron Surface and the Effect of Rubbing Contact on These Interactions. NASA TN D-7283, 1973.

9. Coy, R. C. ; and Quinn, T. F. J.: The Use of Physical Methods of Analysis to Identify Surface Layers Formed by Organosulfur Compounds in Wear Tests. ASLE Trans., vol. 18, no. 3, Jul. 1975, pp. 162-174.

10. Siegbahn, Kai, et al.: ESCA. Almquist \& Wiksel, Uppsala, Sweden, 1967.

11. Swingle, Robert S., II; and Riggs, William M.: ESCA. Crit. Rev. Anal. Chem., vol. 5, no. 3, Oct. 1975, pp. 267-321.

12. Kramer, L. N.; and Klein, M. P.: Chemical Shifts in Core Electron Binding Energies of Iron and Sulfur in Iron Complexes Determined by Photoelectron Spectroscopy. J. Chem. Phys., vol. 51, 1969, pp. 3618-3620.

13. Castle, J. E. ; and Durbin, M. J.: The Surface Composition of Steels Oxidized in Carbon Depositing Atmospheres. Carbon, vol. 13, 1975, pp. 23-31. 
14. Winograd, Nicholas; et al. : X-Ray Photoelectron Spectroscopic Studies of Interactions in Multicomponent Metal and Metal Oxide Thin Films. Sci., vol. 184, no. 4136, May 1974, pp. 565-567.

15. Atkinson, S. J.; Brundle, C. R. ; and Roberts, M. W.: Ultra-Violet and X-Ray Photoelectron Spectroscopy (UPS and XPS) of $\mathrm{CO}, \mathrm{CO}_{2}, \mathrm{O}_{2}$, and $\mathrm{H}_{2} \mathrm{O}$ on Molybdenum and Gold Films. Faraday Discuss. Chem. Soc., no. 58, 1974, pp. 62-79.

16. Carver, J. C.; Schweitzer, G. K.; and Carlson, Thomas A.: Use of X-Ray Photoelectron Spectroscopy to Study Bonding in $\mathrm{Cr}, \mathrm{Mn}, \mathrm{Fe}$, and Co Compounds. J. Chem. Phys., vol. 57, no. 2, July 1972, pp. 973-982. 
TABLE I. - PROPERTIES

OF USP MINERAL OIL

USED FOR WEAR TESTS

Viscosity, $(\mathrm{N})(\mathrm{sec}) / \mathrm{m}^{2}$

At $37.8^{\circ} \mathrm{C}$. . . 0.06

At $98.9^{\circ} \mathrm{C}$. . 0.007

Specific gravity

At $15.6^{\circ} \mathrm{C}$. 0.888

At $25^{\circ} \mathrm{C}$. . . 0.883

Typical lot analysis, ppm

Sulfur .....4 4

Iron ...... 80

Chromium . . < $<0.01$

Nickel ...... 8

TABLE II. - BINDING ENERGIES OF SULFUR (2p), OXYGEN (1s), AND IRON $\left(2 \mathrm{p}_{3 / 2}\right)$ IN SOME REPRESENTATIVE COMPOUNDS

\begin{tabular}{|c|c|c|c|c|c|}
\hline $\begin{array}{l}\text { Sulfur }(2 p) \text { com- } \\
\text { pound }\end{array}$ & $\begin{array}{l}\text { Binding en- } \\
\text { ergy, } \\
\text { eV }\end{array}$ & $\begin{array}{l}\text { Oxygen (1s) } \\
\text { compound }\end{array}$ & $\begin{array}{c}\text { Binding } \\
\text { energy, } \\
\text { eV }\end{array}$ & $\begin{array}{l}\text { Iron }\left(2 p_{3 / 2}\right) \\
\text { compound }\end{array}$ & $\begin{array}{c}\text { Binding } \\
\text { energy, } \\
\mathrm{eV}\end{array}$ \\
\hline $\begin{array}{l}\mathrm{FeS} \\
\mathrm{FeS}_{2} \\
\mathrm{~S} \\
\mathrm{DBDS} \\
\mathrm{R}-\mathrm{S}-\mathrm{S}-\mathrm{R} \\
\mathrm{SO}_{4} \\
\mathrm{FeSO}_{4} \\
\text { Benzyl mercaptide }\end{array}$ & $\begin{array}{r}a, b_{160.7} \\
a_{161.5} \\
a_{,} b_{162.5} \\
b_{162.8} \\
a_{163.3} \\
a_{167.7-167.9} \\
b_{168.0-168.3} \\
g_{162.9}\end{array}$ & $\begin{array}{c}\mathrm{FeO} \\
\mathrm{Fe}_{2} \mathrm{O}_{3} \\
\mathrm{Cr}_{2} \mathrm{O}_{3} \\
\mathrm{H}_{2} \mathrm{O} \text { adsorbed } \\
\mathrm{CO} \text { adsorbed } \\
\mathrm{CO}_{2} \text { adsorbed }\end{array}$ & $\begin{array}{l}b_{529.0} \\
b_{529.4} \\
d_{530.1} \\
e_{532.4} \\
e_{533.2} \\
e_{534.2}\end{array}$ & $\begin{array}{c}\mathrm{Fe} \\
\mathrm{FeO} \\
\mathrm{Fe}_{3} \mathrm{O}_{4} \\
\mathrm{FeS} \\
\mathrm{FeSO}_{4} \\
\mathrm{Fe}_{2} \mathrm{O}_{3} \\
\mathrm{Fe}_{2}\left(\mathrm{SO}_{4}\right)_{3}\end{array}$ & $\begin{array}{r}c_{706.3} \\
c_{706.3} \\
c_{708.8} \\
b, f_{709.5} \\
b_{709.8} \\
c, f_{710.5} \\
b_{712.1}\end{array}$ \\
\hline
\end{tabular}

a 12.

$b_{\text {Ref. } 5 .}$

${ }_{\text {Ref. } 13 .}$

dRef. 14.

e Ref. 15.

${ }^{f}$ Ref. 16.

$\mathrm{g}_{\text {Ref. } 7 \text {. }}$ 
TABLE III. - RELATIVE HEIGHTS OF CHROMIUM AND IRON

OXIDE XPS PEAKS ON MILD AND SEVERE WEAR SCARS

AND ON UNWORN SURFACE AFTER SPUTTERING

\begin{tabular}{|c|c|c|c|c|c|c|}
\hline \multirow{3}{*}{$\begin{array}{l}\text { Sputtering } \\
\text { time, } \\
\text { min }\end{array}$} & \multicolumn{2}{|c|}{ Unworn surface } & \multicolumn{2}{|c|}{ Mild wear scar } & \multicolumn{2}{|c|}{ Severe wear scar } \\
\hline & $\mathrm{Cr}_{2} \mathrm{O}_{3}$ & $\mathrm{Fe}_{2} \mathrm{O}_{3} / \mathrm{FeO}$ & $\mathrm{Cr}_{2} \mathrm{O}$ & $\mathrm{Fe}_{2} \mathrm{O}_{3} / \mathrm{FeO}$ & $\mathrm{Cr}_{2} \mathrm{O}_{3}$ & $\mathrm{Fe}_{2} \mathrm{O}_{3} / \mathrm{FeO}$ \\
\hline & \multicolumn{6}{|c|}{ Relative height of peak } \\
\hline $1 / 2$ & 23 & 77 & 29 & 71 & 26 & 74 \\
\hline 1 & 24 & 76 & 17 & 82 & 27 & 73 \\
\hline 2 & 31 & 69 & 25 & 75 & 27 & 73 \\
\hline 3 & 18 & 81 & 22 & 78 & 20 & 80 \\
\hline Average & 24 & 76 & 23 & 77 & 25 & 75 \\
\hline
\end{tabular}

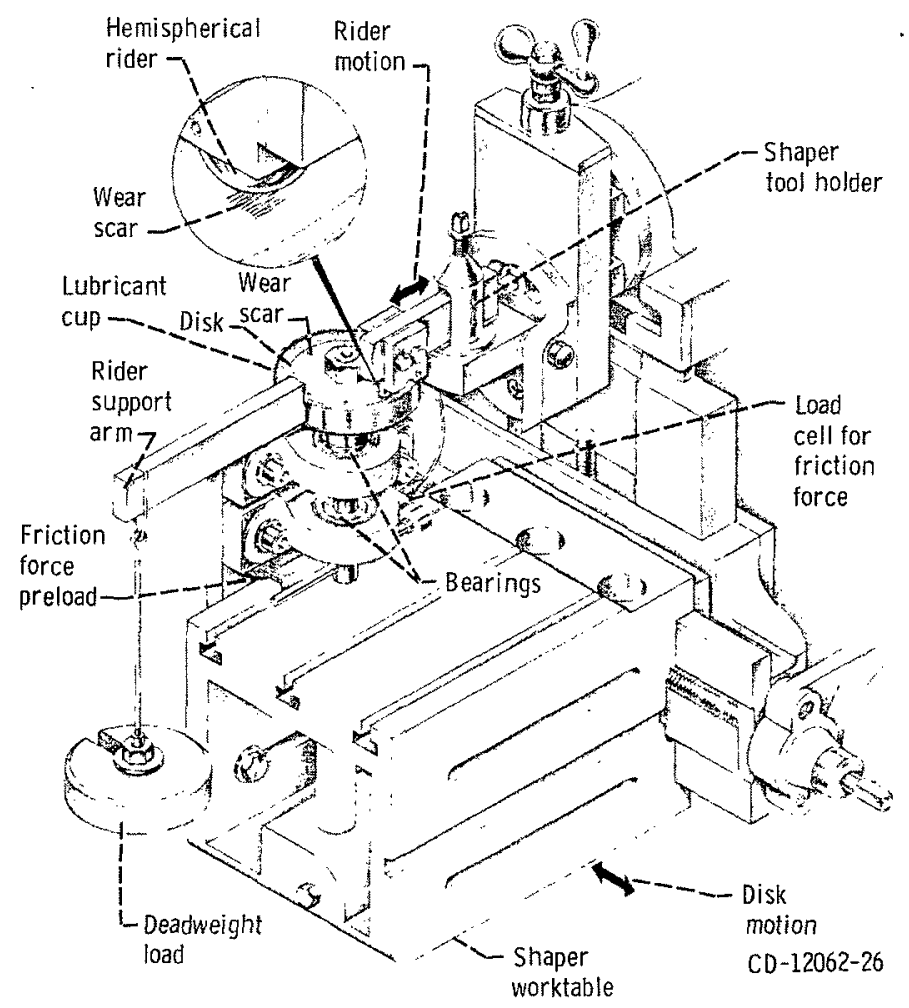

Figure 1. - Wear test apparatus. 


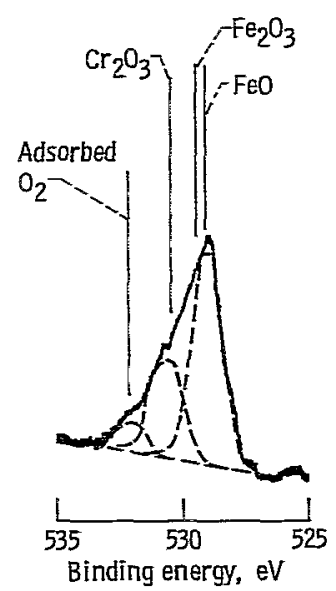

Figure 2 - Oxygen (1s) spectral line from wear test specimen showing binding energies of 1s electron in several compounds (from table II) and resolution of peak obtained with analog curve resolver.

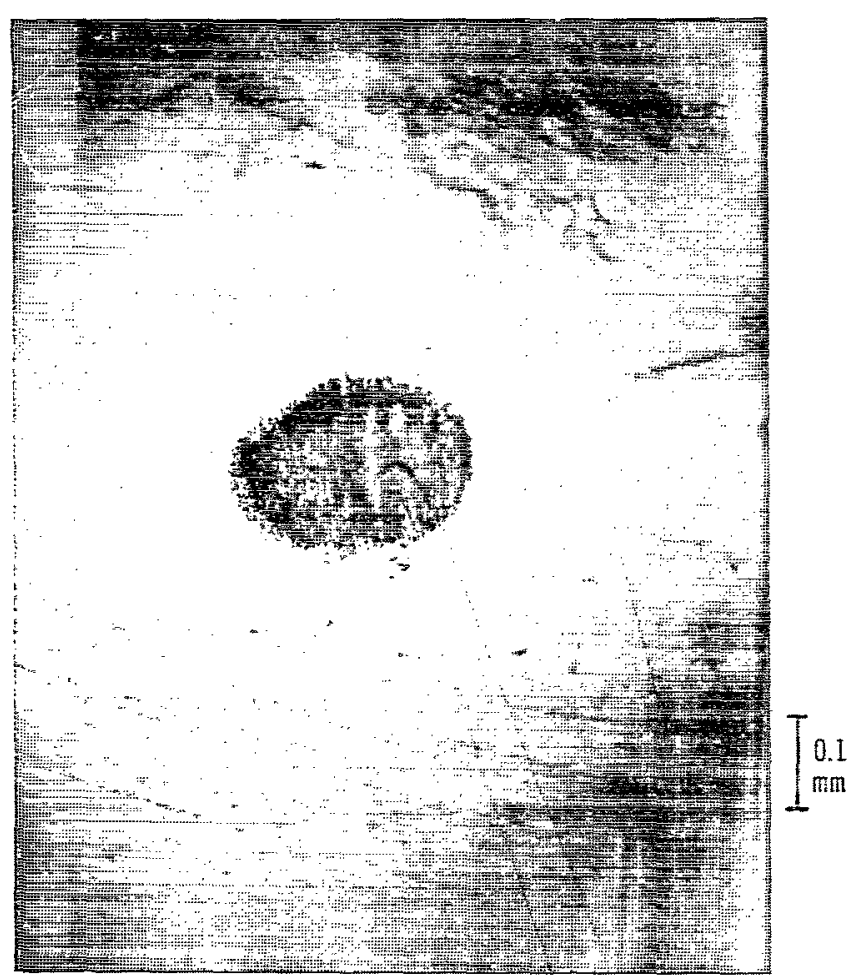

(a) Mild wear scar; load, 22.7 newtons; triction coefticient, $\sim U .1$.

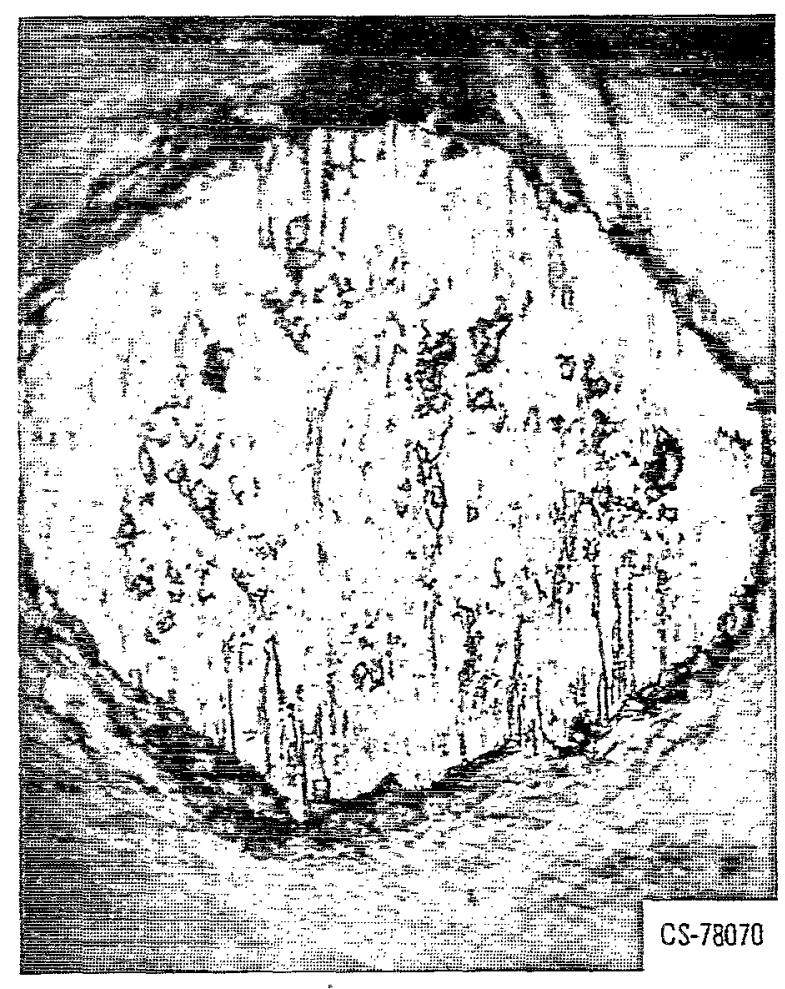

(b) Severe wear scar; load, 135 newtons; trictron coefficient, 0.3 .

Figure 3. - Photomicrographs of typical wear scars on 304 stainiess steel run in mineral ail containing 0.25 percent sulfur as dibenzyl-disulfide. 

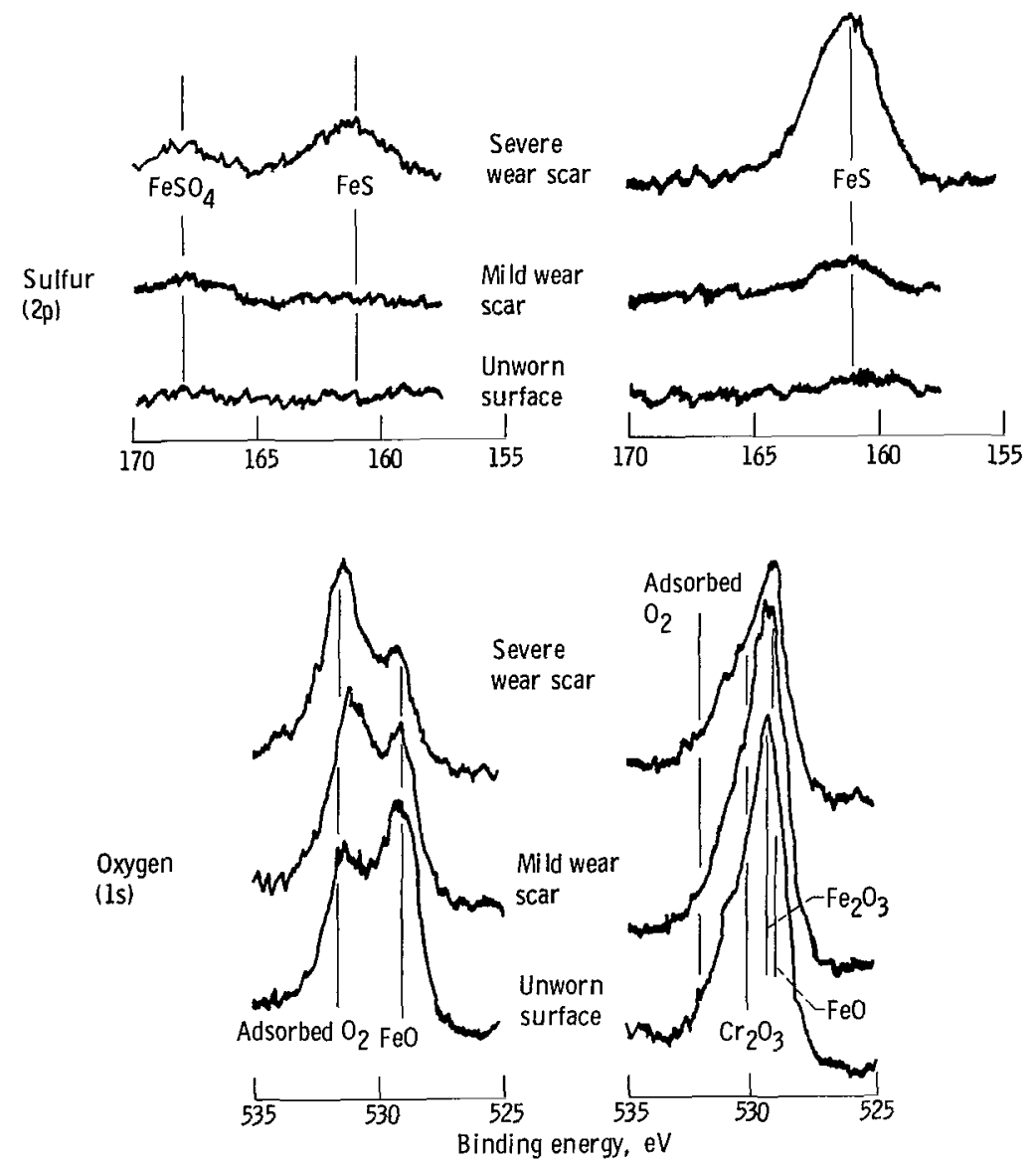
(a) Before sputtering.
(b) After 30 seconds of sputtering.

Figure 4. - Sulfur (2p) and oxygen (1s) XPS features from wear scars and unworn surface. Binding energies of representative compounds are from table II. 


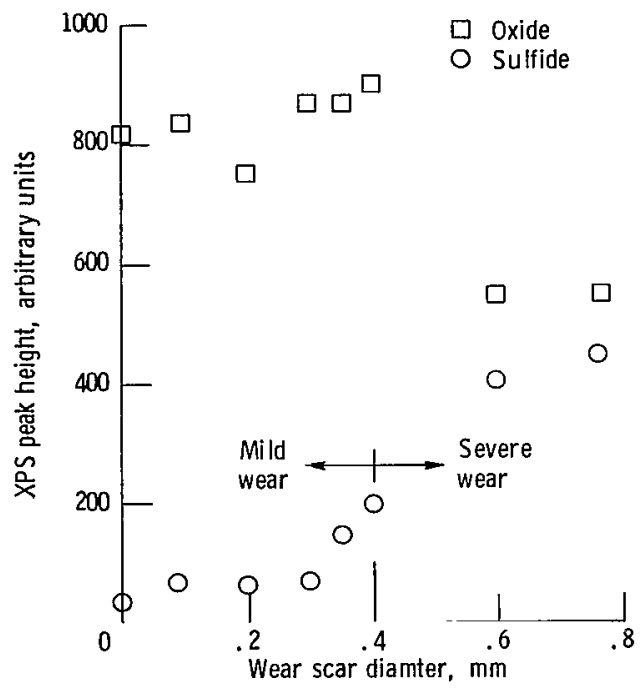

Figure 5. - Oxygen and sulfur XPS peak heights as function of wear scar diameter for 304 stainless steel run in mineral oil with 0.25 percent sulfur as dibenzyl-disulfide. Peaks measured after 30 seconds of sputtering.

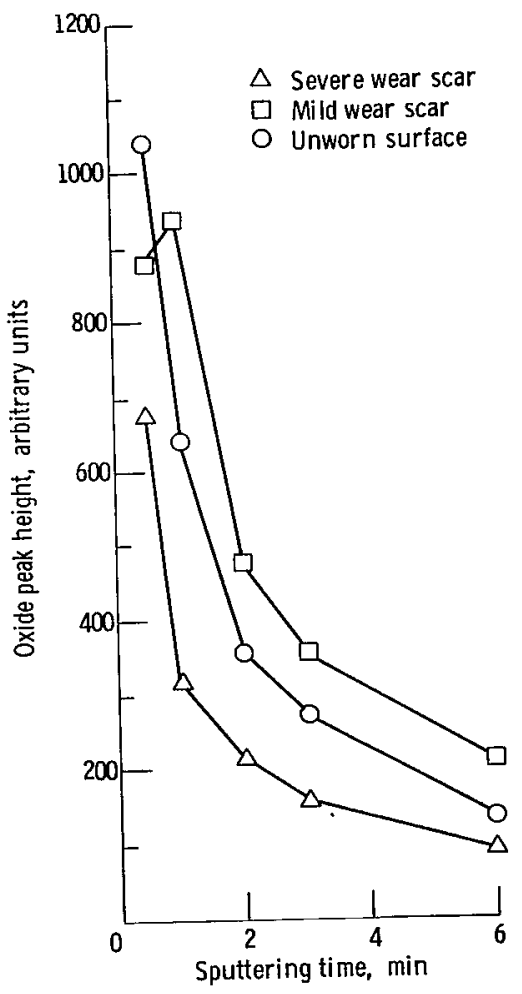

Figure 7. - Oxide XPS peak height as function of sputtering time. Binding energy, 529 electron volts.

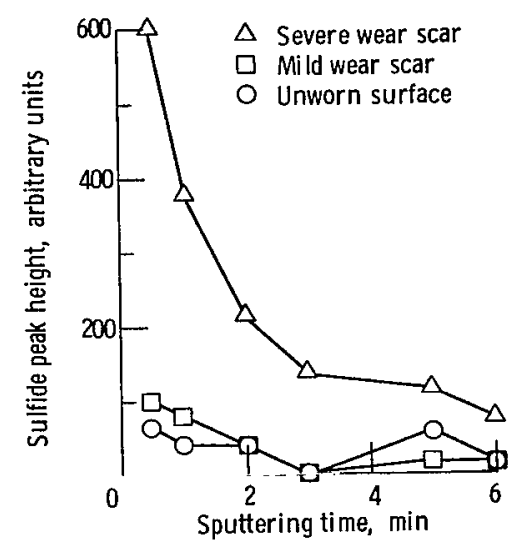

Figure 6. - Sulfide XPS peak height as function of sputtering time. Binding energy, 161 electron volts.

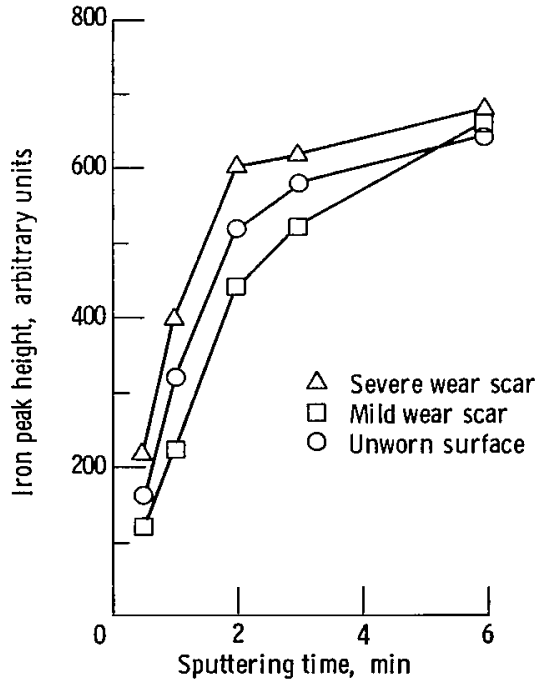

Figure 8. - Iron XPS peak height as function of sputtering time. Binding energy, 706 electron volts. 
305001 C1 O C 770422 S00903DS

DEPT OF THE AIR FORCE

AF MEAPONS LABORATORY

ATTN: TECHNICAL IIBRARY (SUL)

KIRTLAND AFB HU 87117

"The aeronautical and space activities of the United States shall be conducted so as to contribute... to the expansion of buman knowledge of phenomena in the atmosphere and space. The Administration shall provide for the widest practicable and appropriate dissemination of information concerning its activities and the results thereof."

\section{NASA SCIENTIFIC AND TECHNICAL PUBLICATIONS}

TECHNICAL REPORTS: Scientific and technical information considered important, complete, and a lasting contribution to existing knowledge.

TECHNICAL NOTES: Information less broad in scope but nevertheless of importance as a contribution to existing knowledge.

TECHNICAL MEMORANDUMS:

Information receiving limited distribution because of preliminary data, security classification, or other reasons. Also includes conference proceedings with either limited or unlimited distribution.

CONTRACTOR REPORTS: Scientific and technical information generated under a NASA contract or grant and considered an important contribution to existing knowledge.
TECHNICAL TRANSLATIONS: Information published in a foreign language considered to merit NASA distribution in English.

SPECIAL PUBLICATIONS: Information derived from or of value to NASA activities. Publications include final reports of major projects, monographs, data compilations, handbooks, sourcebooks, and special bibliographies.

\section{TECHNOLOGY UTILIZATION} PUBLICATIONS: Information on technology used by NASA that may be of particular interest in commercial and other non-aerospace applications. Publications include Tech Briefs, Technology Utilization Reports and Technology Surveys.

Defails on the availability of these publications may be obtained from:

SCIENTIFIC AND TECHNICAL INFORMATION OFFICE 